\title{
The Research on Status and Future of Inhabitants' Investment and Financial Management
}

\author{
Yang Hao \\ School of computing \\ Shengyang Aerospace University \\ Shengyang China
}

\author{
Zhao Rong \\ School of Economic and Management \\ Shengyang Aerospace University \\ Shengyang China
}

\begin{abstract}
Along with the economical mode of circular economy "reduction, reuse and recycling" development of widely used in social management and practice, as well as the circulatory system of supply chain management and the improvement of laws and regulations, logistics and recycling more and more people's attention. Global automotive industry faces a growing shortage of natural resources and serious destruction of the ecological environment, reverse logistics is of circular economy theory in supply chain management applications. Research used car recycling development situation and countermeasures of logistics, conducive to world resources recycling, recycling of used vehicles lurk huge value.
\end{abstract}

Keywords-reverse logistics; used cars; problems; countermeasu

\section{INTRODUCTION}

With the continuous development of China's automobile industry and the increasing use of automobiles by inhabitants, the number of scrapped cars is also increasing. Therefore, it is necessary to establish a used vehicle recycling system. The effective recycling and utilization of waste vehicles can not only improve the living environment of human beings, but also reduce raw material cost, save energy consumption and increase employment opportunities. It can save nearly $60 \%$ of energy, $70 \%$ of raw materials and reduce cost by $50 \%$ or so. At present, developed countries have established a relatively complete system of legal norms related to scrapped cars, and a fairly complete scrapped car recycling system. We have gradually seen the benefits brought by scrapped cars related activities. In China, the recycling of used vehicles just begins.

\section{RESOURCE REVERSE LOGISTICS OVERVIEW}

\section{A. The concept of reverse logistics}

Reverse logistics has been defined in many ways, and the more professional and accurate general definition is: the process of planning, managing and controlling for the cost effective flow of raw materials, in-process inventory, finished goods and related information from the point of consumption to the point of origin for the purpose of recapturing value or proper disposal, which is contrary to traditional supply chain. In short, it can be classified into two categories: First, reverse logistics mainly refers to the reverse flow of objects formed by the repair and returns of defective products, and the return of containers used for transportation from the buyer to the supplier; Second, it refers to the waster materials logistics, which is mainly the reverse flow of articles formed by the collection, processing, packaging and hauling of products which lose their use value in economic activities according to the actual needs and the distribution of these products to specialized disposal sites.

\section{B. The concept of resource recycling}

Resource recycling mainly refers to the maximization of the valuable wealth contained in waste products, through modern technology and processing, under normal conditions of market operation, to make it resource to be recycled, to achieve the goal of materials saving and environment protection and so on, and to support the cyclic development of social and economic development cycle.

\section{THE STATUS AND ANALYSIS OF USED CAR RESOURCE REVERSE LOGISTICS}

\section{A. The status of the recycling of used cars abroad}

There are a great number of scrapped cars in developed countries every year, but they have formed a circulative system from the design, production, and sales to the recycling of vehicles. Next, a case study will be made on that in Japan and the United States, to analyze the status of the resource recycling of used cars in foreign countries.

\section{1) The United States}

The United States is among a few countries which focused on the recycling of used cars from an early period, and has made remarkable achievements. The automobile recycling system in the U.S. primarily involves disassembly service suppliers, shredding service suppliers and non-ferrous metal separation service suppliers. Despite of the significant technological breakthrough in the recycling of residual material and energy in the scrapping of cars, the scrapped residual is usually treated as garbage. The reverse logistics of used cars is mainly operated by scrapped cars recycling and disassembly industry, and according to statistics, there have been tens of thousands of used cars recycling enterprises, which have established an effective circulative system.

\section{2) Japan}

In Japan, nearly 5 million scrapped cars every year are processed through the recycling network established by professional recycling companies, third-hand dealers and 
manufacturers and so on. The Japanese government's goal is to achieve an automobile recycling rate of $95 \%$ by 2015 .

\section{B. Domestic scrap car recycling development status}

In China, the recycling of used cars started late, and there was no standardized management system established until the beginning of the 1980s. In the present stage, we can not be optimistic about the development of the related fields in China. In 2007, the number of cars that should be scrapped is 3 million to 6 million, but the data of 2006 shows that only 380,000 cars were disassembled. A large part of the vehicles have not been processed effectively, which will result in a waste of resources, and the performance of those vehicles will cause more serious social problems. In March 2008, the pilot project of remanufacturing of automobile parts started and first selected 14 pilot enterprises for remanufacturing, including three vehicle production enterprises of FAW, JAC and Chery. China gradually pay more attention to the field of used cars recycling.

\section{RESEARCH ON THE LOGISTICS MODEL OF USED CARS RECYCLING AND ITS DECISION-MAKING}

\section{A. The classification and comparison of automobile recycling modes}

Under the constraints of extended producer responsibility, manufacturers have to be responsible for their own products in the whole life circle. In this section, according to the different jobs involved in by car manufacturers as the major participators in the reverse logistics activities, the recycling modes are divided into four types:

automobile manufacturer direct recycling;

distributor recycling;

joint operation;

third-party recycling.

The direct recycling by automobile manufacturers means that the automobile manufacturing enterprises are directly responsible for the reverse logistics activities of recycling, transportation, storage, disassembly, remanufacturing and disposal of scrapped cars and undertake the relevant responsibilities and cost.

\section{B. Distributor recycling and then manufacturer processing mode}

Distributor recycling and then manufacturer processing mode means that the distributors get products from the manufacturers and sell them, and are also responsible for the recycling of products returned by the customers and transferred to the manufacturers. The manufacturers handle the products recycled, to finish the reverse logistics though the forward logistics channels, as shown.

By recycling products through distributors, the manufacturers can not only recycle the used products, but also promote the sales of new products by the means of replacing the old with the new, which is an activity beneficial to both the manufacturers and the distributors.

\section{Joint operation mode}

Joint operation mode refers to the cooperation of enterprises in the same industry, to establish the relevant handling process in the form of bundling to provide logistics services for the cooperative enterprises and even the enterprises not in cooperation.

\section{Third-party recycling mode}

Third-party recycling mode means that the automobile manufacturers sign contracts with third parties, to let them undertake the recycling and processing responsibilities on behalf of the manufacturers by means of paying and so on The process is shown in Figure 3.4. Manufacturers pay fees to a third party, and then the third party complete the appropriate processing procedures. Through third-party recycling, the enterprises can reduce cost; In addition, the shared recycling system allows third-party logistics companies to realize scale economy, while the manufacturers can reduce recycling cost.

1) Analysis of the selection of the used automobiles recycling modes

Factors influencing the selection of the used automobile resource recycling modes

The recycling mode influences the recycling efficiency, as well as the the economic and social benefits of enterprises. For any enterprise, the recycling mode of reverse logistics can not be selected randomly, but shall be based on the comprehensive consideration of various factors. Through analysis in many aspects from the perspectives of strategy, operation, management and technology, the automobile manufacturers establish a reverse logistics model fit for their own business according to their own requirements

\section{a) Strategic factors}

The scale and strength of enterprises. The scale and strength of enterprises may be the most important factor influencing the selection of the recycling mode. The large and medium-sized enterprises have strong financial ability and are extremely competitive in the production and marketing of one or a series of products. Besides, they also have excellent logistics management talents and the ability to create their own reverse logistics systems.

The product features of enterprises. The enterprises engaged in the production of conventional products are generally in large scale, and use relatively steady raw materials and produce products with steady structure, so they can adopt the mode of manufacturer direct recycling or distributor recycling. Therefore, proper funding can guarantee the standardization of equipment, so as to improve the operational efficiency of enterprises.

\section{b) Economic factor}

Enterprises' goal of technological improvement. With the wide use of reverse logistics in enterprises, the efficient assembly of products is no longer the unique goal of product design and manufacture. However, it must be taken into full consideration of the requirements whether products can adapt to processing and recycling and whether they can be smoothly dismantled. The enterprises that select the manufacturer recycling mode and distributor recycling mode are directly responsible for product recycling, so they will continuously improve the design of products and set the design oriented requirements as one of their goals for structure design, in order to save the cost of reverse logistics and dismantling. In this way, it will be easy to disassemble and maintain the products, and to fully recycle the products after they are scrapped, which reduces the cost. However, those enterprises adopting the joint 
operation mode or third-party recycling mode may think more about the efficient assembly of products, while seldom consider the design for the convenience of recycling and disassembly. This factor reflects the economic indicators shown by the used cars in the selection of recycling modes, mainly including profitability and investment volume.

c) Management factor

The main indicators reflecting management factor are:

Facilities and equipment management ability.

Scrap car recycling process usually requires a lot of facilities, including recycling facilities, testing equipment, processing equipment and transport vehicles, maintenance and management of these facilities is an important factor in business needs to consider.

Information management ability.

When adopting the manufacturer recycling mode, enterprises can realize information sharing, and continuously improve product and service quality by strengthening the management of the recycling information in the enterprise.

2) Comparison and analysis of the ideal mathematical models of the four modes

Assumption 1: reverse logistics cost mainly include variable cost and fixed cost. Fixed cost includes the cost of recycling network construction and fixed equipment purchase and so on, while the variable cost mainly includes unit processing cost ${ }^{C_{d}}$ and unit recycling cost. Because of different degree of specialization and recycling channels, the unit product processing cost of manufacturers, distributors, ventures and third parties will be largely different.

Assumption 2: Throughout all the reverse logistics activities for the implementation of extended producer responsibility, automobile manufacturers (M) are absolutely dominant and able to select the recycling processing mode fit for themselves. Besides, in the competition with the distributor $(\mathrm{R})$, joint operator $(\mathrm{P})$, third party recycling $(\mathrm{T})$, carmakers have an influence on the recycling price $(\mathrm{p})$ and recycling effort $(\mathrm{t})$.

Hypothesis 3: Set the supply function of used cars (S) as the linear increasing function of recycling price, $\mathrm{S}(\mathrm{p}, \mathrm{t})={ }^{s_{o}} \alpha p+\beta t \cdot \mathrm{p}$ is the recycling price, $\alpha, \beta$ are coefficients, t is the effort of recyclers, $S_{o}$ is the number of used cars recycled when the recyclers neither pay for the recycling nor are willing to make effort, and $\pi_{j}^{i}$ is the profit obtained by $\mathrm{j}$ in the mode $\mathrm{i}$.

Automobile manufacturers direct recycling - MC mode

In this mode, the automobile manufacturer directly recycle used cars from the consumers at the price of $p$ and process them on their own, and the automobile manufacturers independently decide the recycling prices. At this moment, they have to build their own recycling network. According to the reference data, the fixed cost of recycling facilities construction investment $\left(C_{L} t^{2}\right)$ is known, and the automobile manufacturers shall also pay recycling fee to the consumers for the used cars, so the profit function of automobile manufacturing enterprises is:

$$
\pi_{M}^{M C}=\left(\omega-c_{d}-p\right)\left(s_{0}+\alpha p+\beta t\right)-C_{L} t^{2}
$$

$$
\partial \pi / \partial p=0, \partial \pi / \partial t=0 \text { : }
$$

Through the optimal first-order conditions, solve for the partial derivatives of $\mathrm{p}, \mathrm{t}$ respectively, and set $\partial \pi / \partial p=0, \partial \pi / \partial t=0$ to get the equations:

$$
\left\{\begin{array}{l}
\partial \pi / \partial p=-s_{0}-\alpha p-\beta t+\left(\omega-c_{d}-p\right) \alpha=0 \\
\partial \pi / \partial t=\left(\omega-c_{d}-p\right) \beta-2 C_{L} t=0
\end{array}\right.
$$

Solve and get:

$$
\left\{\begin{array}{l}
p^{*}=\frac{\left(2 \alpha C_{L}-\beta^{2}\right)\left(\omega-c_{d}\right)-2 C_{L} s_{0}}{4 \alpha C_{L}-\beta^{2}} \\
t^{*}=\frac{\beta\left(s_{0}+\alpha \omega-\alpha c_{d}\right)}{4 \alpha C_{L}-\beta^{2}}
\end{array}\right.
$$

$$
\mathrm{S}(\mathrm{p}, \mathrm{t})={ }^{s_{o}} \alpha p+\beta t
$$

Substitute (3.3) into equation (1) and $\mathrm{S}(\mathrm{p}, \mathrm{t})={ }^{s_{o}} \alpha p$ ${ }_{+} \beta t$, we have:

$$
\begin{aligned}
\pi_{M}^{* M C}=\frac{C_{L}\left(s_{0}+\alpha \omega-\alpha c_{d}\right)^{2}}{4 \alpha C_{L}-\beta^{2}} \\
S^{* M C}=\frac{2 \alpha C_{L}\left(s_{0}+\alpha \omega-\alpha c_{d}\right)}{4 \alpha C_{L}-\beta^{2}}
\end{aligned}
$$

3) Distributor recycling and transferring to automobile manufacturers - RCM mode

Automobile manufacturers are still responsible for handling used cars, and the MC model is different in that the distributors are responsible for collecting used cars from the consumers at the price of $\mathrm{p}$, and then transfer to the manufacturers at the price $p_{0}$ for processing and recycling. The main driving force of the model is that distributors can rebuild their sales networks into recycling networks, in order to save the fixed costs of recycling. The cost required is less than that required for building a new recycling network by $\mathrm{r}$ times $(0<\mathrm{r}<1)$. Here, the automobile manufacturers decide the recycling and transferring price $p_{0}$, and the sales enterprises decide the recycling price $\mathrm{p}$. We can get the function of profit for automobile manufacturers:

$$
\pi_{M}^{R C M}=\left(\omega-c_{d}-p_{0}\right)\left(\mathrm{s}_{0}+\alpha \mathrm{p}+\beta \mathrm{t}\right)
$$

Function of profit for distributors is: 


$$
\pi_{R}^{R C M}=\left(p_{0}-p\right)\left(\mathrm{s}_{0}+\alpha \mathrm{p}+\beta \mathrm{t}\right)-r C_{L} t^{2}
$$

Results obtained through calculation with the method of the similar MC mode above are shown in Table 3.1.

\section{4) Joint operation mode - PC mode}

When companies can not build their own independent reverse logistics platform but must implement extended producer responsibility system, it is an ideal choice to establish a recycling and processing platform through the joint operator. In the recycling activities under this mode, as the cooperative strategic association of the main enterprises, it can utilize the distributor delivery channel and rebuild it into a reverse logistics channel to finish the recycling and transportation of used articles, which is similar to the recycling channel in the RCM mode, and then gather at the joint processing center for handling. The manufacturers pay per unit cost of recycling used materials $c_{d} c_{d}$ and entrusted recycling fee $\mathrm{m}$ to the joint venture. Here, the function of profit for automobile manufacturers in the decision making mode is:

$$
\pi_{M}^{P C}=\left(\omega-c_{d}-m\right)\left(\mathrm{s}_{0}+\alpha \mathrm{p}+\beta \mathrm{t}\right)
$$

The function of profit for the joint venture is:

$$
\pi_{P}^{P C}=\left(m-p_{0}\right)\left(\mathrm{s}_{0}+\alpha \mathrm{p}+\beta \mathrm{t}\right)
$$

The function of profit for distributors is:

$$
\pi_{R}^{P C}=\left(p_{0}-p\right)\left(\mathrm{s}_{0}+\alpha \mathrm{p}+\beta \mathrm{t}\right)-r C_{L} t^{2}
$$

The results calculated is shown in Table 3.1.

5) The third-party recycling mode - TC mode

In order to maintain their core competencies, automobile manufacturing companies choose to work with a third party. In this mode, a manufacturer signs an agreement with a third party, to pay commission fee $m$ to the third party, In the early stage of cooperation, the thirdparty company has not established a strategic association with the main enterprise, and is not able to implement transformation and recycling by borrowing the networks of the distributors but has to build its own network, so the function of profit for the automobile manufacturer is as follows:

$$
\pi_{M}^{T C}=(\omega-m)\left(\mathrm{s}_{0}+\alpha \mathrm{p}+\beta \mathrm{t}\right)
$$

The function of profit for the third party is:

$$
\pi_{T}^{T C}=\left(m-c_{d}-p\right)\left(\mathrm{s}_{0}+\alpha \mathrm{p}+\beta \mathrm{t}\right)-C_{L} t^{2}
$$

The results calculated are shown in TableI.

TABLE I THE OPTIMAL PROFITS OF AUTOMOBILE MANUFACTURERS AND THE NUMBER OF CARS RECYCLED IN DIFFERENT REVERSE LOGISTICS MODES

\begin{tabular}{c|c|c}
\hline & \multicolumn{1}{c}{$\begin{array}{c}\text { Mode } \\
\text { Optimal value }\end{array}$} & $S$ \\
\hline MC & $\frac{C_{L}\left(s_{0}+\alpha \omega-\alpha c_{d}\right)^{2}}{4 \alpha C_{L}-\beta^{2}}$ & $\frac{2 \alpha C_{L}\left(s_{0}+\alpha \omega-\alpha c_{d}\right)}{4 \alpha C_{L}-\beta^{2}}$ \\
\hline RCM & $\frac{r C_{L}\left(s_{0}+\alpha \omega-\alpha c_{d}\right)^{2}}{2\left(4 r \alpha C_{L}-\beta^{2}\right)}$ & $\frac{r \alpha C_{L}\left(s_{0}+\alpha \omega-\alpha c_{d}\right)}{4 r \alpha C_{L}-\beta^{2}}$ \\
\hline $\mathrm{PC}$ & $\frac{r C_{L}\left(s_{0}+\alpha \omega-\alpha c_{d}\right)^{2}}{4\left(4 r \alpha C_{L}-\beta^{2}\right)}$ & $\frac{r \alpha C_{L}\left(s_{0}+\alpha \omega-\alpha c_{d}\right)}{2\left(4 r \alpha C_{L}-\beta^{2}\right)}$ \\
\hline $\mathrm{TC}$ & $\frac{C_{L}\left(s_{0}+\alpha \omega-\alpha c_{d}\right)^{2}}{2\left(4 \alpha C_{L}-\beta^{2}\right)}$ & $\frac{\alpha C_{L}\left(s_{0}+\alpha \omega-\alpha c_{d}\right)}{4 \alpha C_{L}-\beta^{2}}$ \\
\hline
\end{tabular}


Through the comparative analysis of the automobile manufacturers' optimal recycling profit and the recycling amount in the four different modes of used cars reverse logistics, according to calculation results in Table 3.1, it can be seen:

$$
\begin{aligned}
& S_{M C}=2 S_{T C}, S_{R C M}=2 S_{P C} ; \pi_{M}^{M C}=2 \pi_{M}^{T C}, \\
& \pi_{M}^{R C M}=2 \pi_{M}^{P C}
\end{aligned}
$$

The number of used cars recycled through the automobile manufacturers' direct recycling and processing is larger than that through third parties entrusted recycling and processing; the number of used cars recycled through the distributor recycling and automobile manufacturers processing mode is larger than that through joint operation recycling. This indicates that when the used car recycling can make profit, more used cars can be recycled through automobile manufacturer recycling and processing, and MC mode and RCM model are more conducive to the implementation of extended producer responsibility.

\section{CONCLUSION}

As the biggest manufacturing country in the world, China still has a long way to go in the recycling of used cars. In the twenty-first century, technology is the most important competitive power, and the recycling economy fits the theme of contemporary economic development. The recycling of used cars will become a breakthrough for solving the problem of resources shortage, which requires the country and enterprises to establish a sound logistics recycling system, to achieve the purpose of promoting economic development.
With the introduction of appropriate policies, more and more enterprises are facing the pressure to recycle used cars, and begin to see the economic benefit behind used cars resource reverse logistics. Some automobile manufacturers have implemented appropriate logistics plans, and some are making research to find reverse logistics modes fit for their own recycling. The purpose of business is to maximize profit, and there are also many factors which will influence the selection of reverse logistics modes. Therefore, it is required that different enterprises shall select proper reverse logistics management modes, to achieve the purpose of saving cost.

\section{REFERENCES}

[1] Zou Huixia, Jing Haixia. Reverse Logistics Based on Supply Chain Management. China Circulation Economy, 2011, 17 (7) :19-22.

[2] Li Xiangzhou. Status and Trends of Scrap Cars Recycling at Home and Abroad. Resources Recycling, 2012, (2) :22-24.

[3] Chang Yunxiang. Research on Several Key Issues of Reverse Logistics Recycling. Shanghai: Tongji University, 2011.

[4] Zhao Yi. Research on reverse logistics Based Supply Chain. Chengdu: Southwest Jiaotong University, 2011.

[5] Song Shouxu. Research on Key Reverse Logistics Technology for Home Appliances. Hefei: Hefei University of Technology, 2010.

[6] Jin Jiangjun, Pan Yi. Modern Logistics [M]. Peking University Press, December 2010, 1st edition. P61-63

[7] Xiao Yan, Feng Lei, Cai Yuanyuan. Research on Scrapped Car Reverse Logistics System [J]. Value Engineering, 2011, (01).

[8] Hokey Mina, Hyun Jeung Koa, Chang Seong Kob. A genetic algorithm approach to developing the multi-echelon reverse logistics network for product returns[J]. International Journal of Management Science. 2006, (34): 56-69 